\title{
A high linear growth is associated with an increased risk of childhood diabetes mellitus
}

\author{
L. Blom $^{1}$, L. Å.Persson ${ }^{2}$ and G. Dahlquist ${ }^{1}$ \\ ${ }^{1}$ Department of Paediatrics, Sachs' Children's Hospital, Karolinska Institute, Stockholm and \\ ${ }^{2}$ Department of Epidemiology and Health Care Research, University of Umeå, Umeå, Sweden
}

Summary. Insulin release and growth are intimately connected. The aim of the present study was to investigate height and weight in diabetic children from birth to onset of Type 1 (insulin-dependent) diabetes mellitus compared to that in referent children. Data on height and weight were collected from mailed questionnaires and from growth records obtained from the child health clinics and schools in 337 recentonset diabetic children, $0-14$ years old, and from 517 age-, sex-, and geographically matched referent children. A total of 9002 paired height and weight observations were collected. The anthropometric development of the children was expressed as standard deviation scores using the National Center for Health Statistics/Centers for Disease Control (NCHS/CDC) growth reference material. On the average, the diabetic children were consistently taller than the referent children, a finding more pronounced among the boys. The diabetic boys were significantly taller from 7 to 1 years before the clinical onset of the disease, regardless of age at onset. A similar tendency was found for the girls. When mean height from 5 to 1 years before onset was used as a possible risk factor for diabetes, a linearly increasing trend in the odds ratio was found for diabetes in boys (odds ratio $=1.0 ; 1.57$; 2.46 for height standard deviation score values $<0 ; 0-1$ and $>1$, respectively; $p=0.002$ for trend). A similar, but statistically not significant, tendency was found for girls (odds ratio $=1.0 ; 1.44 ; 1.43)$. As regards height increment from birth similar trends in odds ratios were found. Weight-for-height was similar among diabetic and referent children of both sexes. We conclude that diabetic boys tend to be taller and grow faster than referent boys for several years preceding the disease. A similar, but not statistically significant tendency was found among diabetic girls. Our findings indicate that rapid linear growth is a risk factor for Type 1 diabetes in childhood, and may be either a promoter of Type 1 diabetes or else a marker of a physiological mechanism that affects both growth and the pathogenesis of Type 1 diabetes.

Key words: Type 1 (insulin-dependent) diabetes mellitus, growth, childhood, sex difference, epidemiology.
Adequate insulin supply is one of the fundamental prerequisites for normal growth in children [1]. Insulin apparently promotes growth and differentiation both by a direct action and an indirect action via insulin-like growth factors [2].

Studies on growth development after the clinical onset of Type 1 (insulin-dependent) diabetes mellitus have demonstrated a tendency to retarded growth, despite a fair metabolic control $[3,4]$. The results on growth parameters at the clinical onset of Type 1 diabetes are contradictory. In some studies the height at onset is estimated to be greater in diabetic children than in matched control children or compared to national growth standard charts [5-8]. In other studies the height is similar [9]. However, in a recent twin study a significantly reduced growth velocity was observed prior to the clinical onset of Type 1 diabetes in the twins who subsequently developed the disease [10].
During periods of rapid growth, such as puberty, there is an increased demand on the insulin-producing Beta cells because growth hormone is also known to increase the peripheral insulin resistance $[11,12]$. This has been suggested as one explanation of the prominent peak in the incidence of Type 1 diabetes occurring at the time of the maximal growth spurt in both boys and girls $[13,14]$. It is therefore of interest to study whether rapid growth before puberty is also a risk factor for Type 1 diabetes in childhood. Large-scale longitudinal studies describing the growth pattern in diabetic children during the period from birth until the clinical onset of diabetes are lacking. In Sweden, the growth development of all children is recorded at child health clinics and school health care units, and all children who develop diabetes before the age of 15 years are reported to the Swedish Childhood Diabetes Register $[15,16]$. Using this register, a nationwide incident 
Table 1. Number of anthropometric observations among diabetic and referent children

\begin{tabular}{lll}
\hline $\begin{array}{l}\text { Number of } \\
\text { observations }\end{array}$ & $\begin{array}{l}\text { Diabetic children } \\
(\%)\end{array}$ & $\begin{array}{l}\text { Referent children } \\
(\%) \\
(n=337)\end{array}$ \\
\hline $1-9$ & 36.5 & 36.4 \\
$10-19$ & 59.3 & 62.1 \\
$20-30$ & 4.2 & 1.5 \\
\hline $\begin{array}{l}\text { Mean number of } \\
\text { observations }\end{array}$ & 10.9 & 10.2 \\
\hline
\end{tabular}

Table 2. The distribution of the number of height and weight measurements in children who later developed diabetes and in referent children, by age group

\begin{tabular}{llll}
\hline $\begin{array}{l}\text { Number of height and weight measurements } \\
\text { Age group } \\
\text { (years) }\end{array}$ & $\begin{array}{l}\text { Diabetic children } \\
n(\%)\end{array}$ & $\begin{array}{l}\text { Referent children } \\
n(\%)\end{array}$ & $\begin{array}{l}\text { Total } \\
n(\%)\end{array}$ \\
\hline $0-4$ & $2712(73.5)$ & $3915(73.7)$ & $6627(73.6)$ \\
$5-9$ & $654(17.7)$ & $960(18.1)$ & $1614(17.9)$ \\
$10-14$ & $326(8.8)$ & $435(8.2)$ & $761(8.5)$ \\
total & $3692(100.0)$ & $5310(100.0)$ & $9002(100.0)$ \\
\hline
\end{tabular}

case referent study was performed to answer the following questions:

- Do children who develop diabetes have a different growth pattern during periods prior to clinical onset of the disease from that of matched referent children?

- Does the height of diabetic children at the clinical onset of Type 1 diabetes differ from that of carefully matched referent children?

\section{Subjects and methods}

The study was approved by the Ethics Committee of the Karolinska Institute and by the Swedish Data Inspection Board.

In Sweden all children 0-14 years of age with suspected diabetes are referred to paediatric departments. All incident cases of Type 1 diabetes are reported to the Swedish Childhood Diabetes Register which has a level of ascertainment of $99 \%$ [17]. Date of onset is defined as the date of the first insulin injection. On the basis of this register, an incident case referent study was performed from 1 September 1985 to 31 August 1986. For each child two age-, sex-, and geographically-matched referent children were traced through the official Swedish population register. The collection of data by questionnaires has recently been described in detail $[15,16]$.

In the questionnaires the parents reported their children's birth weight and height and current weight and height at the time the questionnaire was answered. With parental consent we were able to collect anthropometric data from child health clinics and schools for 300 of $339(88.5 \%)$ of the diabetic and from 434 of $528(82.2 \%)$ of the referent children participating in the study. Using data from both sources of information -i.e., the questionnaire and the health records - we included 337 diabetic (180 boys and 157 girls) and 517 referent ( 277 boys and 240 girls) children. The age distribution of diabetic and referent subjects is equal because of the design of the study, and recently described in detail [16]. The mean number of paired height and weight observations was 10.9 for the diabetic children and 10.2 for the referent children, with a range of observations per individual between 1-30 (Table 1). Our results are based on 9002 paired height and weight observations. Since the Swedish child health care system includes regularly scheduled visits to the child health care centres during infancy and early childhood, and com- paratively few in late pre-school and school age, the anthropometric measurements early in life dominated in the present study. The proportions of paired measurements in different age groups were almost identical in diabetic and referent children (Table 2). Weight, height and weight-for-height by sex and age were converted to standard deviation scores (SDS), utilizing the National Center for Health Statistics/Centers for Disease Control (NCHS/CDC) anthropometric reference material [18] and the CDC anthropometric software package (CASP) [19]. The NCHS/CDC reference material covers the data of all participating subjects concerning weight and height by age and sex, but weight-for-height is limited to heights between $49-146 \mathrm{~cm}$ for boys and $49-137 \mathrm{~cm}$ for girls and our analysis is limited accordingly.

Height and weight for age and sex and weight-for-height by sex were expressed as mean SDS and $95 \%$ confidence limits for defined periods of time for the whole group of diabetic and referent boys and girls, respectively. They were also sub-grouped for age at the onset of diabetes. Since there were no significant differences in the total number of observations between the diabetic and referent children in different age groups (Table 2), and since the mean numbers of observations for diabetic and referent children were equal (Table 1), these calculations provide a reliable basis for a description of the characteristic growth development patterns from birth onwards in diabetic and referent boys and girls. Height weight, and weight-for-height development by age and sex were described from birth to the clinical onset of the disease in the diabetic children, and for the same period
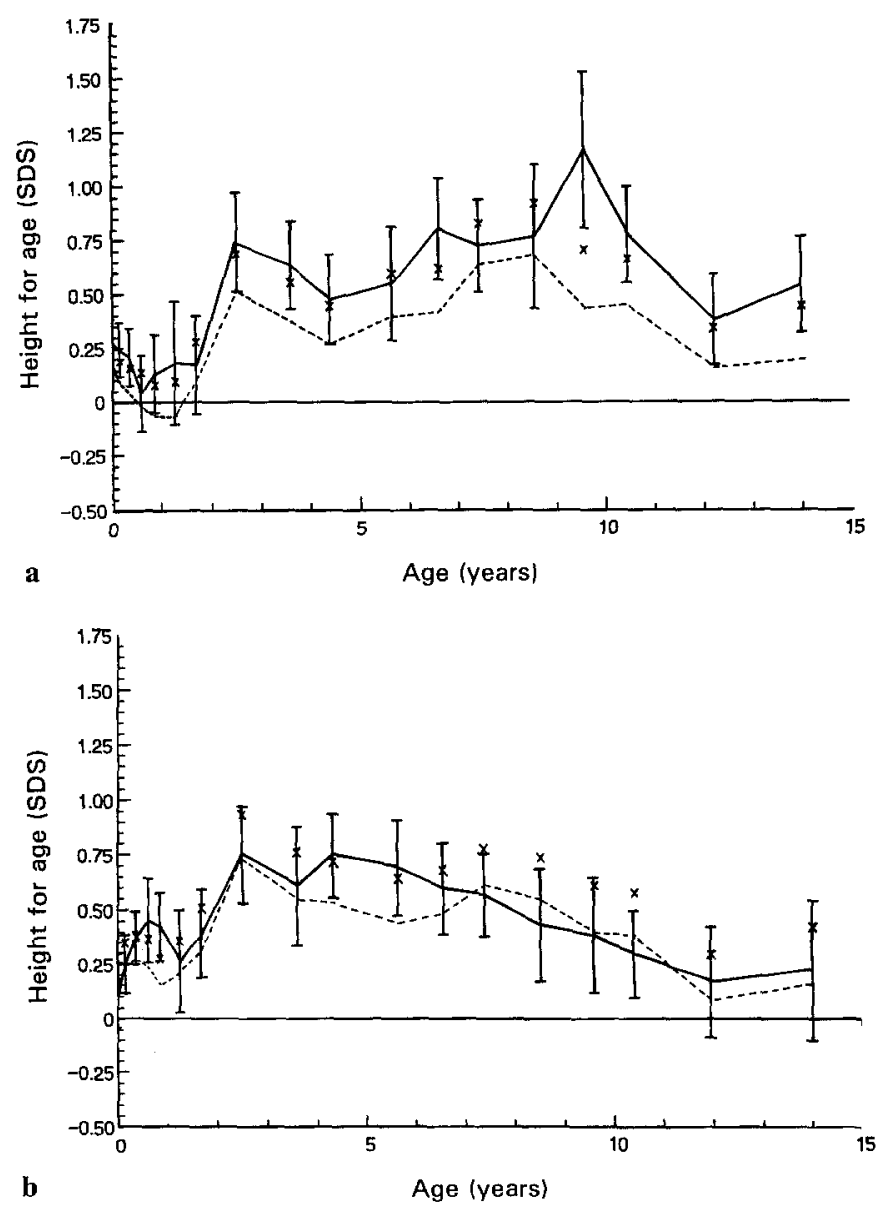

Fig.1a,b. Hight from birth and onwards in $\mathbf{a}$ boys and $\mathbf{b}$ girls. The mean height for age is expressed in standard deviation scores (SDS). The solid line marks the values of the children who developed diabetes, the dotted line the values of the referent children; $95 \%$ confidence intervals of the mean values are marked with solid vertical lines for the diabetic children and the upper corresponding intervals with an $\mathrm{x}$ for the referent children 


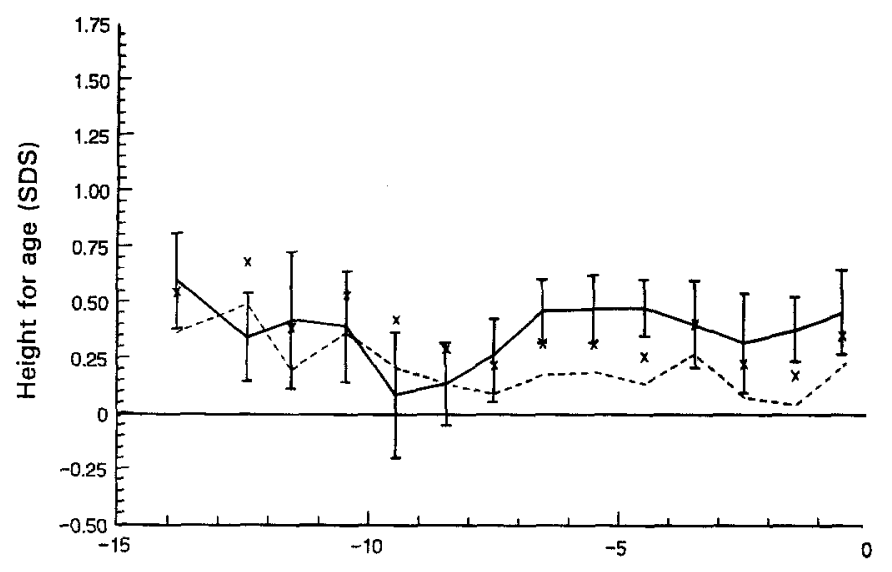

a

Years before onset

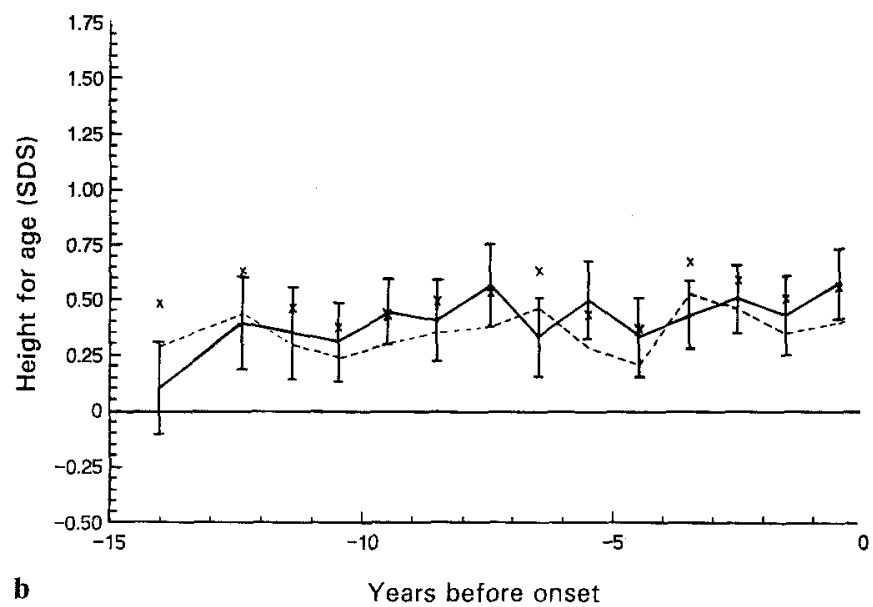

Fig. 2a,b. Height development before clinical onset of Type 1 diabetes in $\mathbf{a}$ boys and $\mathbf{b}$ girls. The mean height, related to clinical onset of Type 1 diabetes, is expressed in standard deviation scores (SDS). The solid line marks the values of the children who developed diabetes, the dotted line the values of the referent children; $95 \%$ confidence intervals of the mean values are marked with solid vertical lines for the diabetic children and the upper corresponding interval with an $\mathrm{x}$ for the referent children

in the matched referent children, but also retrospectively from onset of the disease investigating different periods preceding it.

\section{Statistical analysis}

To evaluate the possible association between different growth patterns and the risk of developing diabetes in childhood, birth height and weight and the mean height and weight values in SDS for each child for the period from 5 to 1 years preceding the clinical onset of diabetes was calculated. The relative risk of developing Type 1 diabetes was estimated as an odds ratio (OR). To assess the impact of change in growth increment over time for the relative risk of developing diabetes, the OR for changes in height and weight, in SDS, between birth and the defined period before clinical diagnosis was estimated. Sufficient basic data to perform these calculations concerning height and weight were available in 714 children and for weight-for-height in 643 children. OR and $95 \%$ confidence intervals were calculated by Miettinen's method [20]. A possible trend in dose-response was analysed by the Mantel-Haenszel extension test. Standardization for confounders was performed by stratification and the standardized OR were calculated by Mantel-Haenszel's method. All statistical analyses were performed using the Quest software developed for the Swedish Medical Research Council by L. Gustavsson, PhD.

\section{Results}

\section{Height and weight development from birth onwards}

The mean attained height for age, expressed in SDS, after birth of the boys who developed diabetes, was consistently higher than that of referent boys, although the $95 \%$ confidence intervals overlapped, with the exception of the 10 th year of age (Fig. $1 \mathrm{a}$ ). In contrast to the boys, the girls who developed diabetes showed no consistent difference in mean SDS for height development, as compared to the referent girls (Fig. 1b). For both diabetic and non-diabetic boys and girls the height in SDS was increased relative to the NCHS/CDC standard. The weight for age showed similar patterns for diabetic and referent children of both sexes.

\section{Height development before the clinical onset of Type 1 diabetes}

Looking retrospectively at height development before the date of clinical onset of the disease and using this date as a cut-off limit for the matched referent children, we note that the boys who developed diabetes were consistently taller than the referent boys from 7 to 1 years before the onset (Fig. 2a) but this difference diminished during the year preceding the onset. The same pattern was found among the boys with an onset of diabetes at $0-4,5-9$ and 10-14 years of age. No such clear difference was found among the girls (Fig. $2 \mathrm{~b}$ ).

\section{Height and weight development as risk factors for Type 1 diabetes}

Height and weight at birth did not affect the risk of developing diabetes later in childhood. In contrast, with regard to the mean height during the 5 to 1 years before the onset of Type 1 diabetes as a risk factor for diabetes, a dose-response relationship between increased height and risk for diabetes was found in boys ( $p$ for trend $=0.002$ ). A tendency towards an increased OR in the taller girls for the same period was present but the trend was not statistically significant ( $p$ for trend $=0.22$ ) (Table 3). To investigate whether weight development might be a primary risk factor for diabetes, the OR for weight-for-height by sex was estimated in the 5 to 1 year-period preceding the disease onset. No significant deviation in OR for the onset of diabetes in overweight children was revealed (Table 3 ).

\section{Height increment from birth}

The height increment $-i$. e., the difference between the height at birth and the mean height value from 5 to 1 years preceding the onset of the disease showed an increased 
Table 3. Relative risk as odds ratio (OR) and $95 \%$ confidence interval (CI) for Type 1 (insulin-dependent) diabetes mellitus and the mean height by age and weight-for-height by age in standard devia- tions scores (SDS) from 5 to 1 years before clinical onset of the disease. Risk estimations are also standardized for Type 1 diabetes in relatives, maternal age and education as confounding factors

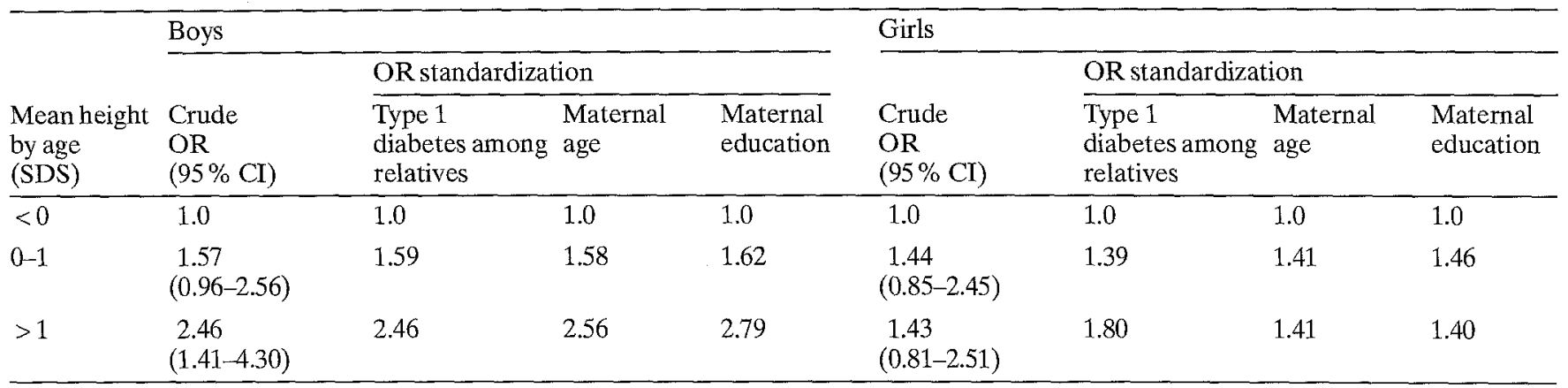

\section{Mean weight-}

for-height

by age

(SDS)

\begin{tabular}{lllllllll}
\hline$<0$ & 1.0 & 1.0 & 1.0 & 1.0 & 1.0 & 1.0 & 1.0 & 1.0 \\
$0-1$ & 0.79 & 0.75 & 0.72 & 0.78 & 0.86 & 0.65 & 0.88 & 0.85 \\
& $(0.50-1.26)$ & & & & $(0.52-1.42)$ & & & \\
& 0.78 & 0.87 & 0.75 & 0.73 & 0.88 & 0.93 & 0.81 \\
\hline
\end{tabular}

relative risk of diabetes in boys ( $p$ for trend $=0.02$ ) and a similar but more irregular tendency in girls ( $p$ for tend $=$ 0.09) (Table 4).

\section{Standardization for confounders}

Social determinants may influence growth development in children [21]. Since social factors such as maternal age and education have recently been shown to influence the relative risk of developing Type 1 diabetes among the present subjects [16], the analyses were also made and standardized for these factors as well as for Type 1 diabetes among relatives. No significant deviations were found between the crude and standardized odds ratios (Tables 3 and 4 ).

\section{Discussion}

Because the Swedish child health care system is responsible for the welfare of almost all children from birth up to adolescence, the conditions are good for performing a study concerning growth parameters from birth onwards. The fact that growth development of the individual child is carefully documented in growth records enabled us to acquire unbiased data.

The most striking finding was a consistent increase, most obvious in boys, in the height of children who developed diabetes. The finding does not seem to be explained by endocrinological changes exclusively during puberty, since the same tendency was found in boys with a clinical onset of diabetes of 0-9 years of age as well as in a group with onset at 10-14 years of age. Moreover, when regarding the height increment from birth as a risk factor, a dose-response relationship was found for boys between height development and a risk for developing Type 1 diabetes in childhood.

This phenomenon may have various explanations. A rapid growth determined by genetic factors and mediated by hormonal influences may increase the peripheralinsulin demand and thus affect the clinical onset in an individual who has a decreased Beta-cell mass caused by an unrelated immunological Beta-cell destructive process. In this perspective a rapid growth in itself may be considered a direct risk factor for diabetes in growing individuals. Alternatively, the basic mechanism may be a genetically determined tendency to hyperinsulinaemia, leading both to an accelerated growth [2] and perhaps also to an increase in the vulnerability of the Beta cell. In this context it is interesting to note that episodes of hypoglycaemia occur in pre-diabetic individuals [22]. Furthermore, the hyperfunctioning Beta cell has proved to be increasingly susceptible to the Betacell cytotoxic action of lymphokines such as interleukin 1 and tumour necrosis factor [23]. In this perspective, a rapid growth may be regarded rather as a marker for Type 1 diabetes during childhood. It may also be speculated that the early lesions of the Beta cells may evoke an over-compensation or an early remission-type phase with hyperinsulinism. This event may lead to an increased growth velocity, eithervia the insulin receptors or via the insulin-like growth factor receptors [24].

Although similar height development patterns were noted in boys and girls who developed diabetes, the pattern was more evident and consistent in boys. The reason for this sex difference is not clear. One may speculate whether it may be partly because girls enter puberty about 2 years earlier than boys and therefore in the present study a larger proportion of the girls would have stopped growing when they entered the study. This might have reduced the difference between the diabetic and the referent girls. 
Table 4. Relative risk as odds ratio $(O R)$ and $95 \%$ confidence interval (C) for Type 1 (insulin-dependent) diabetes mellitus and height increment expressed as the mean difference in standard deviation scores (SDS) between birth and the period from 5 to 1 years before

\begin{tabular}{|c|c|c|c|c|c|c|c|c|}
\hline \multirow[b]{2}{*}{$\begin{array}{l}\text { Mean difference } \\
\text { in height } \\
(\mathrm{SDS})\end{array}$} & \multicolumn{4}{|l|}{ Boys } & \multicolumn{4}{|l|}{ Girls } \\
\hline & $\begin{array}{l}\text { Crude } \\
\text { OR } \\
(95 \% \mathrm{CI})\end{array}$ & $\begin{array}{l}\text { Type } 1 \\
\text { diabetes } \\
\text { among } \\
\text { relatives }\end{array}$ & $\begin{array}{l}\text { Maternal } \\
\text { age }\end{array}$ & $\begin{array}{l}\text { Maternal } \\
\text { education }\end{array}$ & $\begin{array}{l}\text { Crude } \\
\text { OR } \\
(95 \% \mathrm{CI})\end{array}$ & $\begin{array}{l}\text { Type } 1 \\
\text { diabetes } \\
\text { among } \\
\text { relatives }\end{array}$ & $\begin{array}{l}\text { Maternal } \\
\text { age }\end{array}$ & $\begin{array}{l}\text { Maternal } \\
\text { education }\end{array}$ \\
\hline$\overline{<0}$ & 1.0 & 1.0 & 1.0 & 1.0 & 1.0 & 1.0 & 1.0 & 1.0 \\
\hline$>1$ & $\begin{array}{l}2.03 \\
(1.15-3.57) \\
\end{array}$ & 1.96 & 1.98 & 2.17 & $\begin{array}{l}1.54 \\
(0.86-2.77) \\
\end{array}$ & 1.53 & 1.42 & 1.54 \\
\hline
\end{tabular}

onset of the disease. Risk estimations are also standardized for Type 1 diabetes in relatives, matemal age and education as confounding factors
In a very recent prospective twin study from the United Kingdom concerning 12 identical twin pairs, consisting of originally healthy twins and their co-twins with Type 1 diabetes, the seven twins who later developed Type 1 diabetes showed a decreased growth velocity for a new period of about 1 year prior to the clinical onset of the disease [10]. In our study, relying on routine measurements in child health centres and schools, a detailed description of the growth pattern during the year before the onset of diabetes could not be performed, but the tendency towards a diminishing difference in mean heights during this period may reflect the same phenomenon as described in the twin study. The tendency of the diabetic boys to be taller several years before clinical onset of the disease compared to matched subjects, found in our study, could not be verified in the twin study because of the identical inheritance of monozygotic twins resulting in very similar height development within these twin pairs [25].

Obesity is a well-known risk factor for peripheral insulin resistance and hyperinsulinaemia. However, the analysis of weight development as well as weight for height by age and sex from 5 to 1 years before the onset of diabetes showed no relationship to the risk of developing the disease. Therefore, we consider that the height rather than weight development is the principal risk factor in this context.

The finding that both the diabetic and the referent children were slightly taller and heavier than assumed in the NCHS/CDC anthropometric reference material [18] was probably due to the ethnically based differences in the growth characteristics of the subjects participating in the present study and those who contributed to the growth data in the referent system. The secular trend of growth may also partly explain this phenomenon [26].

We conclude that, children, who later develop diabetes, especially boys, tend to be slightly but consistently taller, although not heavier, than matched referent children from early childhood up to the year of the clinical onset of Type 1 diabetes.

Also mean height from 5 to 1 years preceding the onset of diabetes shows a dose-response relationship to the risk - for boys - of developing Type 1 diabetes. An accelerated height development from birth up to the 5 to 1 years be- fore the onset of the disease is associated with an increased risk of Type 1 diabetes in childhood, even when standardized for possible confounders, such as maternal age and education and Type 1 diabetes among relatives.

Acknowledgements. The Swedish childhood diabetes study is supported by grants from the Swedish Medical Research Council, (project No. B87-27X-07531-02B), the Karolinska Institute, Nordisk Insulin Foundation, the Novo Company, the Swedish Diabetes Association, the Swedish Medical Society, Svenska Diabetesstiftelsen, Samariten Foundation and Förenade Liv Mutual Life Insurance Company.

\section{References}

1. Berger M, Berchthold P (1985) Insulin as growth factor. In: Marble A, Krall LP, Bradley RF, Christlieb AR (eds). Joslin's diabetes mellitus. Lea \& Febiger, Philadelphia, pp 101-102

2. Hill DJ, Milner RD (1985) Insulin as a growth factor. Pediatr Res 19:879-886

3. Sterky G (1963) Diabetic schoolchildren. Acta Paediatr Scand 144 (Suppl): $1-39$

4. Evans N, Robinson VP, Lister $J$ (1972) Growth and bone age of juvenile diabetics. Arch Dis Child 47:589-593

5. White $P$ (1960) Childhood diabetes. Its course and influence on the second and third generations. Diabetes 9:345-355

6. Drayer NM (1974) Height of diabetic children at onset of symptoms. Arch Dis Child 49:616-620

7. Edelsten AD, Hughes IA, Oakes S, Gordon IRS, Savage DCL (1981) Height and skeletal maturity in children with newly-diagnosed juvenile-onset diabetes. Arch Dis Child 56: 40-44

8. Songer TJ, LaPorte RE, Tajima $N$ et al. (1986) Height at diagnosis of insulin-dependent diabetes in patients and their nondiabetic family members. Br Med J 292: 1419-1422

9. Emmerson AJ, Savage DC (1988) Height at diagnosis in diabetes, Eur J Pediatr 147:319-320

10. Leslie RD, Lo S, Millward BA, Honour J, Pyke DA (1991) Decreased growth velocity before IDDM onset. Diabetes 40: $211-$ 216

11. Amiel SA, Sherwin RS, Simonson DC, Lauritano AA, Tamborlane WV (1986) Impaired insulin action in puberty, a contributing factor to poor control in adolescents with diabetes. $\mathrm{N}$ Engl J Med 315: 215-219

12. Lindgren $F$, Dahlquist $G$, Efendic S et al. (1987) Glucose-induced insulin response and insulin sensitivity are not related to HLAtype but to age in young siblings of Type 1 (insulin-dependent) diabetic patients. Diabetologia 30:727-732 
13. LaPorte RE, Fishbein HA, Drash AL et al. (1981) The Pittsburg insulin-dependent diabetes mellitus registry. The incidence of insulin-dependent diabetes mellitus (IDDM) in Allegheny County, Pennsylvania (1965-1976) Diabetes 30: 279-284

14. Dahlquist G, Blom L, Holmgren G et al. (1985) The epidemiology of diabetes in Swedish children 0-14 years - a six-year prospective study. Diabetologia 28: 802-808

15. Dahlquist G, Blom L, Tuvemo T, Nyström L, Sandström A, Wall S (1989) The Swedish childhood diabetes study - Results from a nine year case register and a one year case-referent study indicating that Type 1 (insulin-dependent) diabetes mellitus is associated with both Type 2 (non-insulin-dependent) diabetes mellitus and autoimmune disorders. Diabetologia 32: 2-6

16. Blom L, Dahlquist G, Nyström L, Sandström A, Wall S (1989) The Swedish childhood diabetes study - social and perinatal determinants for diabetes in childhood. Diabetologia 32: 7-13

17. Nyström L, Dahlquist G, Rewers M, Wall S (1990) The Swedish Childhood Diabetes Study. An analysis of the temporal variation in diabetes incidence 1978-1987. Int J Epidemiol 19: 141-146

18. Vital and health statistics (1977) NCHS growth curves for children, birth-18 years, United States series 11 - number 165 , DHEW Publication Number (PHS) 78-1650. Department of Health, Education and Welfare, Hyattsville

19. Jordan MD (1986) The CDC anthropometric software package. The Centers for Disease Control, Atlanta

20. Miettinen O (1976) Estimability and estimation in case-referent studies. A J Epidemiol 103: 226-235
21. Habicht JP, Martorell R, Yarbrough C, Malina RM, Klein RE (1974) Height and weight standards for pre-school children. How relevant are ethnical differences in growth potential? Lancet I: 611-614

22. Scandellari C, Federspil G, de Palo C, Erle G (1977) Hypoglycaemia in pre-diabetes. Panminerva Med 19: 101-106

23. Nerup J, Mandrup-Poulsen T, Molvig J, Helqvist S, Wogensen L, Egeberg J (1988) Mechanisms of pancreatic beta-cell destruction in Type 1 diabetes. Diab Care (Suppl 1): 16-23

24. Froesch ER, Zapf J (1985) Insulin-like growth factors and insulin: Comparative aspects. Diabetologia 28: 485-493

25. Fishbein S (1977) Intra-pair similarity in physical growth of monozygotic and/or dizygotic twins during puberty. Ann Human Biol 4: 417-430

26. Tanner JM (1978) Foetus into man: physical growth from conception to maturity. Open Books, London, pp 150-153

Received: 30 September 1991

and in revised form: 16 January 1992

\section{Dr. L.Blom}

Department of Pediatrics

Sachs' Children's Hospital

P.O. Box 17912

S-11895 Stockholm

Sweden 